\title{
BMJ Open How do nursing students experience the clinical learning environment and respond to their experiences? A qualitative study
}

\author{
Majid Najafi Kalyani, ${ }^{\oplus}$ Nahid Jamshidi, Zahra Molazem, ${ }^{\ominus}$ Camellia Torabizadeh, \\ Farkhondeh Sharif
}

To cite: Najafi Kalyani M, Jamshidi N, Molazem Z, et al. How do nursing students experience the clinical learning environment and respond to their experiences? A qualitative study. BMJ Open 2019;9:e028052. doi:10.1136/ bmjopen-2018-028052

- Prepublication history for this paper is available online. To view these files, please visit the journal online (http://dx.doi. org/10.1136/bmjopen-2018028052).

Received 21 November 2018 Revised 28 May 2019 Accepted 3 July 2019
Check for updates

(C) Author(s) (or their employer(s)) 2019. Re-use permitted under CC BY-NC. No commercial re-use. See rights and permissions. Published by BMJ.

Nursing, School of Nursing and Midwifery, Shiraz University of Medical Sciences, Shiraz, The Islamic Republic of Iran

Correspondence to

Dr Zahra Molazem;

molazem@sums.ac.ir

\section{ABSTRACT}

Introduction On entry into the clinical environment, nursing students are confronted with many challenges. It is a common problem throughout the world, including Iran. Although many studies have been conducted on the problems of nursing students in the clinical environment, limited information is available on nursing students' experiences of the clinical learning environment and the way they respond to these experiences. Identifying nursing students' experiences is essential to develop interventions to reduce challenges.

Objective This study aimed to explore nursing students' experiences in a clinical learning environment and the way they responded to these experiences.

Design The present study was conducted based on the qualitative research design of the grounded theory methodology.

Setting This study was conducted at schools of nursing in academic settings in Iran.

Participants The participants included 19 nursing students, 4 nursing instructors and 3 clinical nurses. Methods The data were collected using semistructured interviews, field notes and observation, and were analysed using Strauss and Corbin's approach.

Results Students, as a result of the inadequacy of the educational environment, were faced with 'confusion of identity', stating this as their main concern. When confronted with this concern, they employed specific strategies, some of which prevented them from getting into unpleasant conditions. These strategies did not help students solve their problems and also prevented them from accepting their professional roles and responsibilities. Conversely, some other strategies led them to advanced professional development and enabled them to accept their role and the clinical environment.

Conclusion According to the results of this study, educational policymakers should focus on improving the clinical environment. Identifying professional models and increasing their influence on management, education and clinical education, as well as teaching positive and constructive strategies, will promote positive strategies in coping with inadequate educational contexts. This is necessary for the professional development of nursing students.
Strengths and limitations of this study

- The study, by performing a grounded theory research, provided increased, indepth understanding of how nursing students experience the clinical learning environment and the way they respond to this experience.

- Combining resources and using the experiences of educators, clinical nurses and students provided multiplied validity to this study and helped identify a more comprehensive image of the process under investigation.

- The information gained from this study may be useful in improving clinical environments and educational contexts.

- Due to the sociocultural uniqueness and the context-bound relevance of the qualitative findings of this study, repetition of the study is required in other countries and cultures.

\section{INTRODUCTION}

Nursing students should employ their knowledge and skills in clinical environments to acquire the required qualifications for taking care of patients, and their success depends to a great extent on efficient clinical training. ${ }^{1}$ Clinical training is regarded as the heart and essence of learning and education in nursing. ${ }^{2}{ }^{3}$ Furthermore, clinical learning environment plays an important role in turning nursing students into professionals and preparing them to function as nurses. ${ }^{4}$

A clinical learning environment is a combination of several physical, psychological, emotional and organisational factors affecting the students' learning and how they confront the environment. ${ }^{56}$ This environment has considerable effects on students' positive learning and emotional well-being. ${ }^{78}$ Furthermore, students get acquainted with the realities of their profession and functions of nursing in this environment. ${ }^{9}$ However, the clinical learning environment has been 
referred to as a reason for either quitting or continuing the nursing profession. ${ }^{10}$ The complexity of this environment and the events involved causing tension make it hard to be controlled. ${ }^{11}$ On entry into the clinical environment, nursing students are confronted with many challenges and problems which affect their learning in that environment. ${ }^{10}$ Quitting the profession, fear, anxiety and confusion have been mentioned as the main reasons for nursing students' unpreparedness and concern in clinical learning environments. ${ }^{213}$ Bachelor nursing studies last for 4 years in Iran, during which students enter clinical education and clinical learning environments. The major part of nursing education in clinical environments in Iran begins in the second term and continues until the end of the eighth term. ${ }^{10}$

The results of the study by Papathanasiou et $a l^{14}$ indicated a considerable gap between students' expectations and clinical learning environments, which confronted them with problems in the clinical learning environment. Identification and elimination of the problems in clinical learning environments reduce nursing students' emotional and behavioural problems in these environments. ${ }^{1516}$ Despite the severe shortage of nurses and the need for nurse training in Iran, there is not enough incentives to enter this profession, and many cases of leaving the profession, ${ }^{17}$ lack of motivation ${ }^{18}$ and psychological problems occur after entry into the clinical environment. ${ }^{2}$

The quality of clinical practice in Iran is determined by two main factors, namely the nursing care delivery method and the nurse to patient ratio. Within the clinical field, nursing students and nurses take care of patients from various ethnic groups and different cultures based on the case method. ${ }^{19}$ Several studies have been conducted on nursing students' clinical training in Iran. One study conducted by Peyrovi $e t a l^{19}$ demonstrated that nursing students were afraid of providing care in clinical learning environments. Also in the research by Joolaee et $a l^{10}$, nursing students reported fear and anxiety in clinical environments. Similarly, the students participating in the study carried out by Hanifi et $a l^{18}$ stated that becoming a nurse was one of their major concerns in clinical environments. Long-term experience (20-30 years) of researchers in clinical education of nursing students also shows that nursing students undergo a lot of changes after entering clinical setting, causing mental and psychological problems, lack of motivation, and the decision to leave the profession.

Although the above-mentioned studies have addressed nursing students' problems and challenges in clinical environments, none of these has investigated how students experience the learning environment and the way they respond to this experience. Considering the problems of Iranian nursing students after entering the clinical environment, the effects of this environment on students' professional learning and future, and the existing gap in the literature, and given that no comprehensive research has been conducted in this regard, this study was performed using a grounded theory approach

\begin{tabular}{lll}
\hline \multicolumn{2}{l}{$\begin{array}{l}\text { Table } 1 \\
\text { study }\end{array}$} & Characteristics of the students participating in the \\
\hline Identifier & Age (years) & Sex \\
\hline S1 & 22 & Male \\
S2 & 20 & Female \\
S3 & 20 & Female \\
S4 & 23 & Female \\
S5 & 23 & Female \\
\hline S6 & 25 & Female \\
S7 & 20 & Female \\
\hline S8 & 22 & Female \\
S9 & 20 & Female \\
S10 & 23 & Female \\
S11 & 23 & Male \\
S12 & 21 & Male \\
S13 & 21 & Female \\
S14 & 21 & Female \\
S15 & 21 & Female \\
S16 & 20 & Female \\
S17 & 21 & Female \\
S18 & 20 & Female \\
S19 & 19 & Female \\
\hline & & \\
\hline
\end{tabular}

for profound understanding of how students experience things (behaviours, events and interactions) on entering clinical environments and attending clinical departments. This would pave the way for improvements in clinical training and reduction of probable problems in the clinical environment.

\section{METHODS}

\section{Study design}

Qualitative research with the grounded theory approach was used as the appropriate method to answer the research question. Grounded theory approach is a deep study of clinical practices, behaviours, and attitudes of individuals and groups. Since grounded theory focuses on social processes and is related to the context, it is a suitable method to answer the research question and to describe the social processes lying in the data. ${ }^{20}$

\section{Participants}

In this research, 19 nursing students as key informants were first selected based on purposive sampling (table 1). Then, to complete the connections between the categories that emerged and to extract the process in the data, four instructors (table 2) and three clinical nurses (table 3) were interviewed based on theoretical sampling until data saturation was achieved. The selection criteria for nursing students included internship experience in clinical learning environments and willingness to participate in the research and to express their personal 
Table 2 Characteristics of the instructors participating in the study

\begin{tabular}{lll}
\hline Identifier & Age (years) & $\begin{array}{l}\text { Educational } \\
\text { experience } \\
\text { (years) }\end{array}$ \\
\hline 11 & 38 & 5 \\
12 & 32 & 10 \\
13 & 40 & 4 \\
14 & 35 & 9 \\
\hline
\end{tabular}

experiences. It should be noted that the instructors and nurses had at least 5 years of work experience.

\section{Data collection}

Semistructured personal interviews were used to collect data from the students, instructors and nurses from October 2014 to May 2017. The interviews were decided to be conducted at Shiraz Faculty of Nursing and to last between 40 and $70 \mathrm{~min}$, as agreed by the participants. It should be noted that five nursing students were interviewed twice.

The interviews began with the following questions: 'What did you experience after entering the clinical leaning environment', 'What happened during your clinical practice', 'How did you feel at that time', and 'What did you do'. The instructors and nurses were also asked to share their experiences about exposing students to the clinical learning environment. The interviews were recorded and transcribed. Field notes and observations were employed as well.

\section{Data analysis}

Data collection and analysis were performed simultaneously using Strauss and Corbin's approach. In this method, the data were examined several times and analysed (as in the example in table 4) using the three steps of open, axial and selective coding until theoretical saturation was achieved. The data were collected by the authors (ZM, NJ and MNK). All authors participated in the data analysis; they talked about the codes and categories and reached an agreement. Data analysis was conducted during the data collection process as follows. At the beginning, the audio files of the recorded interviews and observations were transcribed. In the analysis for open coding, the texts of the interviews and observations were read several times and the main concepts were extracted and coded.

Table 3 Characteristics of the nurses participating in the study

\begin{tabular}{lll}
\hline Identifier & Age (years) & $\begin{array}{l}\text { Clinical } \\
\text { experience } \\
\text { (years) }\end{array}$ \\
\hline N1 & 33 & 4 \\
N2 & 36 & 10 \\
N3 & 35 & 7 \\
\hline
\end{tabular}

After this, similar codes were placed in one category by constant comparison. In axial coding, the initial categories formed in the open coding were compared, and those that were similar to each other were rooted in a common axis. At this stage, the categories were related to their axial categories in order to provide more precise and complete explanations of the phenomenon. In the third step or the selective coding, constant comparison was used to determine the relationships among the categories and to search for the process involved in the data. The researchers also looked for the core variable and the existing process in the data. ${ }^{21}$ Memoing and diagramming were used as well.

\section{Rigour}

Regarding the trustworthiness of the data, credibility was established through member check, data collection triangulation and prolonged engagement. In this regard, the texts of the interviews and the derived codes were returned to the participants $(n=10)$ and they were asked to comment on the researchers' perceptions of their statements and to correct any variations. Indeed, peer check was performed by five expert supervisors of nursing and experts in qualitative research. They also supervised the process of interviewing, coding and categorisation. Moreover, maximum variation of sampling (in terms of sex and academic term) enhanced the confirmability and credibility of the data. ${ }^{21}$

\section{Patient and public involvement}

Patients were not involved in this study. The study participants included nursing students, instructors and clinical nurses.

\section{RESULTS}

The findings of the present study (figure 1) showed that, due to the inadequacy of the clinical environment, nursing students were faced with confusion of identity and stated this as their main concern. Students in confrontation with this concern used two sets of strategies according to the condition. Some of these strategies prevented them from getting into unpleasant situations. These strategies did not help students solve their problems and prevented them from accepting their professional roles and responsibilities. On the other hand, some other strategies promoted the students' professional development and helped them better embrace their clinical environment and professional responsibilities. Supportive systems in this process would also facilitate students' professional development.

\section{Inefficient educational context}

When in clinical training environment, nursing students realised that it lacked the required efficiency. Inefficient educators, unfavourable educational plans and inappropriate clinical environment were the components of this inefficient educational context. 
Table 4 An example of data analysis

\begin{tabular}{llll} 
Text of the interview & Code & Subcategory Category \\
\hline "There were lots of dressings and lots of things connected to & Fear from the unknowns & Fear & Emotional \\
them (the patients). I had never seen these; it's scary...I have no & Fear from negative feedback & flares \\
idea how to operate them; it's so bad." (S16) & Fear from harming patients & \\
"It has happened to me a lot... They shiver...I asked some & & \\
$\begin{array}{l}\text { and they replied 'we're afraid of being told that we are making } \\
\text { mistakes." (N2) }\end{array}$ & & &
\end{tabular}

\section{Inefficient educators}

According to students' experiences, some instructors and nurses did not have adequate efficiency to educate students and transfer knowledge to them. Some instructors' failure to provide sufficient details on medications, procedures and required care was among the items mentioned by the students.

...In one of the internships, the teacher provided us with no explanations on what the medication was, how it was to be dissolved, and what complications it had... (S13)

Some instructors' improper assessment of students, inflexibility, lack of experience, lack of clinical skills and failure to respond to students' questions were other items stated by the students.

...Master students are now set as instructors. They neither have sufficient knowledge, nor do they know how to communicate and teach... (S5)
Furthermore, some nurses in clinical environments were not able to respond to students' questions properly.

\section{Unfavourable educational planning}

Lack of correspondence between the length of internship courses and the specified objectives, as well as between the times of theoretical and practical courses, resulted in students encountering challenges when in the clinical environment.

In the same term that we have orthopedics, we have to attend internship at that department. Before learning about the diseases and care, we are encountered with patients at the ward, which causes us not to learn well... (S18)

Based on the students' experiences, educational focus on performing routine tasks and repetitive departments in different internships restricted the opportunity to learn more.

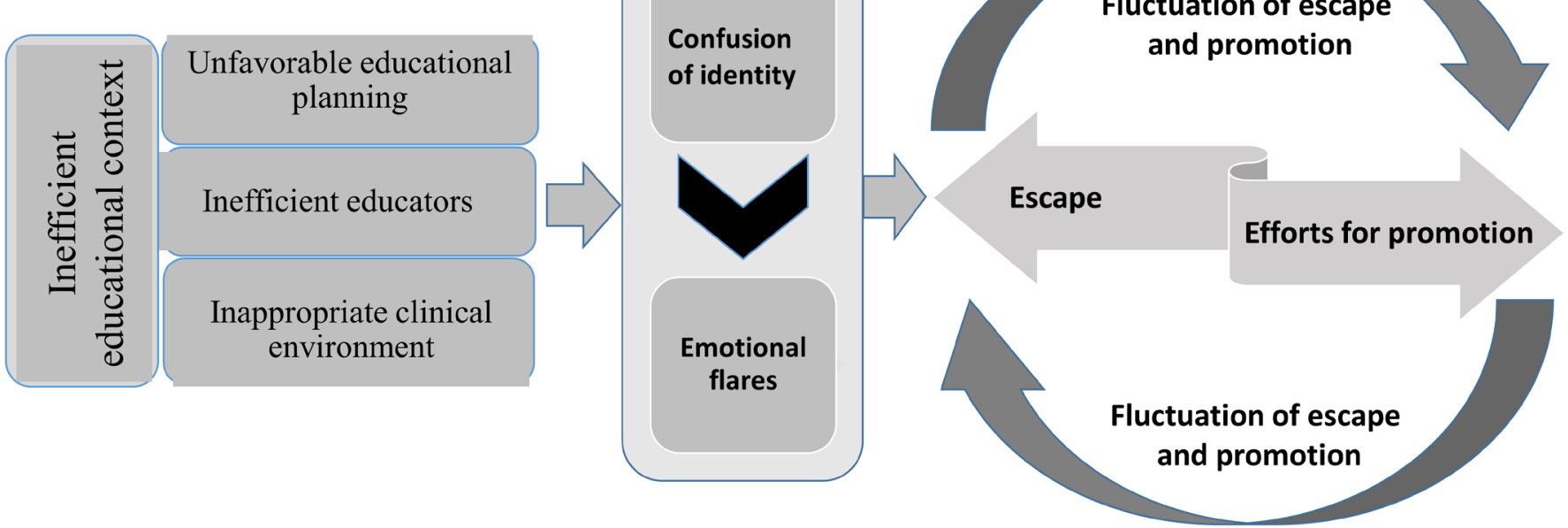

Figure 1 Nursing students' experiences and strategies in the clinical learning environment. 
...We haven't seen many cases at all; we go to the department and everything is repeated... (S4)

From the students' perspective, limitations in the curricula deprived them of the requirements for entering the clinic in terms of knowledge and clinical and communication skills. Furthermore, admission in nursing profession with no regard to the correspondence between the students' characteristics and the field, or its mandatory or blind selection by some students, made them spiritually unprepared to attend clinics and receive the required instructions.

\section{Inappropriate clinical environment}

Some nurses' negative attitudes towards the students' presence in the department, lack of support, and nurses' and patients' mistrust caused an unsupportive atmosphere in clinics, which was very unpleasant to the students.

...Well, they (nurses) are biased, saying 'oh, students are there again!'...Then, they always seek for problems with our work... (S10)

Students observed unpleasant interactions in clinical departments that challenged them. They kept complaining about the nurses' neglect or indifference towards them, as well as the staff's non-cooperation.

...Department nurses behave so badly, just as if you're saying something bad to them. They don't cooperate at all. (S16)

Furthermore, educational injustice and discrimination between nursing and medical students were major problems in clinical learning environments.

...I was reviewing a patient's record when the nurse took it away from me very roughly. She would say nothing to a medical student though... (S5)

Moreover, lack of facilities and unavailability of the needed equipment led to waste of time and delay in patient care; such an educational environment was unpleasant to the students. Nurses also found the physical space inappropriate to the number of students in the department.

\section{Confusion of identity}

There was no clear description of tasks for nurses and students, which was why they did not know what they were responsible for. Non-professional tasks performed by nurses, for instance, caused a negative attitude towards nursing and confusion about its functions.

...We do things at the department that attendants are responsible for; for example, when patients want us to clean their beds.... (S4)

Furthermore, the mismatch between expectations and reality and the difference between what they have been taught in classrooms and what they observe in clinical environments intensified the confusion. Instructors' and nurses' different expectations also increased the confusion and conflicting roles.

...We instructed a student how to communicate with the patient and go through the nursing process. The student was explaining to the patient, but the nurse said there was no need for too much explanation... (I2)

Nurses with negative attitudes towards their career brought this attitude to the students and doubted them in accepting their role as a nurse.

... Nurses themselves keep telling me "what a pity you selected this field'. They speak ill of it...They are by no means motivated, they keep groaning at departments. Then, how can I have a positive attitude towards nursing... (S17)

...I feel that nurses are treated like servants, which is not at all the case. A nurse also studies, as in all other fields, and what she does is scientific... (S10)

These factors caused nursing students in clinical environments to change their attitudes towards nursing and be confused in accepting their professional identities.

\section{Emotional flares}

When confronted with the problems and challenges in educational opportunities and clinics, students were faced with psychological problems, fear and stress. Their fear and stress in clinical learning environments could be rooted in the unknowns, equipment and fear from harming the patients.

...There were lots of dressings and lots of things connected to them (the patients). I had never seen these; it's scary...I have no idea how to operate them; it's so bad... (S16)

Another source of students' fear in clinical learning environments was receiving negative feedback from instructors, patients' companions or nurses.

...It has happened to me a lot...They shiver...I asked some and they replied 'we're afraid of being told that we are making mistakes'... (N2)

Hopelessness was another psychological reaction created under the influence of nurses' attitudes. Discriminatory behaviours and an unsupportive atmosphere in clinical environments, as well as the negative attitude towards nursing students and nursery in clinical departments and the society, caused an inferiority complex, a sense of humiliation or deficiency in self-confidence in students. Furthermore, some nurse instructors' unfriendly behaviours intensified these feelings.

...When instructors don't talk to us and don't treat us properly, we have no self-confidence to be able to serve patients; we are upset to the extent that we have no incentive to work... (S14) 
The unsupportive, unfriendly atmosphere sometimes caused the students to cry or jitter.

\section{Fluctuation of escape and promotion}

Nursing students used two sets of strategies based on their conditions in the clinical environment as an inadequate educational context. Some of these strategies made it possible for them to escape from unpleasant situations. These strategies did not help students solve their problems and prevented them from accepting their professional roles and responsibilities. On the contrary, some other strategies promoted students' professional development and helped them embrace their clinical environment and professional responsibilities and reduce negative emotional responses. In this study, fluctuation of escape and promotion was recognised as the core variable.

\section{Escape}

Sometimes, the students tried to deal with unpleasant behaviours by neglecting or staying silent in order to reduce tension and stress and to avoid the increase of such behaviours.

...Whenever we enter the department, nurses say 'the clumsy are there again,'...We said nothing, kept silent, and just stopped and looked... (S8)

Some students tried to avoid the nurses' unpleasant, destructive behaviours. They also tried not to get stuck in situations that required knowledge and skills to prevent stress and irritation.

...I can't perform electrocardiography and get stressed when I need to do it...I don't select a patient for whom I have to do so; I avoid these opportunities in order not to get stressed... (S18)

However, the students sometimes chose a different method; they denied the reality, that is, lack of knowledge and skills, and tried to pretend that they held high skills or the required knowledge for caretaking.

...I never admit that I don't know something...either to a teacher or to a patient...never...I don't know, in fact, and I'm also stressed... (S1)

Escaping from responsibility was another strategy, which was sometimes adopted by the students. Lack of correspondence between the students' personalities and the field also resulted in escape from responsibilities. This was manifested as a waste of time or failure to do the assignments through which the students tried to encounter the unpleasant conditions in the clinical environments.

...Students really come to the department and don't work willingly; they always seek for a way to escape... They attend the department conference, but they aren't prepared; they make excuses... (I1)

\section{Efforts for promotion}

Some students used a strategy to grow and promote due to a sense of internal commitment as well as the need for understanding and improving their practical skills. In this way, support from nearby people, including peers and instructors, was helpful. They tried to find themselves in the environment and to understand who they are, what their duties are, and how they can establish a relationship and gain the trust of patients and nurses. In this way, the students tried to better understand their roles and responsibilities and to increase their practical knowledge and skills. Therefore, they identified some nurses and educators with high care and skill levels and good relationships as their models to improve their performance and reduce the stress caused by their lack of knowledge and skills.

...I definitely choose the instructor with proper behavior as my role model, and try to learn from her... (S16)

Furthermore, some students tried to be responsible towards the patients due to their intrinsic sense of commitment and made efforts to gain patients' trust and satisfaction and provide better care. Thus, they overcame their lack of interest and incentive, and they satisfied themselves and promoted their own performance.

...even if I'm not interested in nursing, I try to do my job properly to satisfy the patients since I feel responsible now; this makes me interested at least... (S1)

Search for information was another important measure taken by the students to manage the stress that resulted from unpreparedness and fear.

The students stated that they used support from their friends, peers and some instructors to reduce their psychological problems and overcome their fear and negative feelings towards clinical environments, so that they could appear with confidence and perform the assigned tasks.

\section{DISCUSSION}

The findings of this study expanded nursing students' main concern in the clinical education environment and the overall strategies used to deal with it.

It is one of the instructors' and nurses' important obligations to provide nursing students with training and support on entry in clinical environments and help them accept their roles as nurses. However, the findings of the present research, as well as those of some other studies, have indicated that nurse instructors and nurses lacked the required efficiency, knowledge and skills for training students. ${ }^{22}$ Furthermore, the results of the present study demonstrated that defects in educational planning reduced the students' preparedness to enter the field. The wide gap between theoretical and clinical education results from educational planning methods in the field. ${ }^{24}$ The results of the research by Pourghane ${ }^{23}$ indicated that 
repetitive topics in clinics resulted in negative clinical experiences, and this had to be taken into consideration.

Students enter clinics with insufficient preparedness and with their own conceptions of clinics and nursing. They discover conflict between their expectations and learnt subjects and the reality in clinics once they are encountered with an unsupportive atmosphere, nurses' negative behaviours and attitudes, and so on. This finding is in line with those of other studies. ${ }^{14}{ }^{25}$ Abazary $e t a l^{26}$ stated that nursing students' entry into clinical environments caused interference between their and nurses' responsibilities and the resultant problems. Factors causing problems between students and the department staff include lack of correspondence between education and treatment, rejection of criticism, insufficient equipment provided to students and failure to consider the students' list of responsibilities.

Improper clinical work environments and lack of correspondence between reality and the students' preconceptions resulted in nursing students' negative view of their career and the decision to quit. ${ }^{17}$ This is a major reason for quitting the career and withdrawing from the field after entering clinical environments. ${ }^{27}$ Nonetheless, most students enter nursing profession with positive attitudes towards the values of caretaking and expect to learn it as a caretaking career. ${ }^{28}$ Of course, students' personality traits are of great importance with regard to their preparedness to work in clinical environments and their role as nurses. Iranian university entrance exam only assesses participants' theoretical knowledge and educational talent. A study conducted in Iran demonstrated that $44 \%$ of students did not hold personality traits appropriate to the nursing career, and about $77 \%$ of them had little knowledge of the field when selecting it. ${ }^{29}$ Therefore, an important point for admitting students to this field is to assess its correspondence with their personality traits. Another important factor in the students' achievement of nursing purposes and proper professional performance is to establish good relationships with the treatment team. However, students hardly have such experiences and consequently encounter conflicts in accepting their profession. $^{30}$

The interpersonal relationship between the instructors and clinical nurses and the students plays an important role in the development of students' personal and professional identities. ${ }^{31}$ Furthermore, instructors' and clinical nurses' negative relationships with and behavioural and verbal aggression towards students are a major factor in the development of stress in students, creating a sense of inefficiency and disqualification. ${ }^{32}$ Establishing proper relationships with students and supporting them in clinical environments both facilitate the learning process and result in professional socialisation. ${ }^{33}$

When confronted with stressful, unpleasant factors in clinical environments, students try to use coping strategies. ${ }^{34}$ Some studies have demonstrated that students tended to use positive ${ }^{35}$ or avoidance strategies. ${ }^{3637}$ Coping strategies including transference, staying optimistic and problem-solving were other solutions to reduce students' stress. ${ }^{34}$ Gaining support from friends has also been one of the most important strategies employed by students. ${ }^{37}$ According to the results of the study by Vaghee $e t a l^{38}$, training in communication skills reduced the employment of the 'escape from troublesome situations' and avoidance strategies, and could enforce the 'seeking for social support' strategy, increase efforts to obtain information and emotional support from others, and increase the employment of 'responsibility' and 'problem solution' strategies, as well as analytical efforts to solve problems in stressful situations.

It is essential that health and education policymakers have a special focus on improving clinical environments and educational contexts. Identifying professional models and increasing their influence on management, education and clinical education, as well as teaching positive and constructive strategies, help strengthen and promote positive strategies in coping with inadequate educational contexts.

\section{Limitations of the study}

This study only focused on discovering the experiences of Iranian nursing students, clinical nurses and instructors. Thus, further studies in other cultures are needed to make the results more generalisable.

\section{CONCLUSION}

The present study showed that continued attention is required to minimise unsupportive atmosphere in the clinical environment, as well as negative attitudes towards nursing students and nursing profession in clinical departments and the society. In this context, educators and nurses should be aware that they, as proper role models, can motivate students and enhance their clinical knowledge and skills. In addition, educators and nurses can be effective in helping nursing students properly confront the challenges of the clinical environment. Use of constructive strategies that lead to professional development of nursing students should be enforced with the necessary instructions, and at the same time faculties and clinical environments are coordinated. In this way, clinical authorities are informed about students' expectations and clinical environments are improved, eventually enhancing students' preparedness and capabilities before entering the clinics.

Acknowledgements This article was extracted from the $\mathrm{PhD}$ dissertation written by NJ. The authors would like to thank Ms A Keivanshekouh at the Research Improvement Center of Shiraz University of Medical Sciences for improving the use of English in the manuscript.

Contributors Study design and conception: MNK, NJ, ZM, FS, CT. Data collection: MNK, NJ, ZM. Data analysis and interpretation: MNK, NJ, ZM, FS, CT. Manuscript writing: MNK, NJ, ZM. Critical revision of the manuscript: MNK, NJ, ZM, FS, CT. Final approval of the manuscript: MNK, NJ, ZM, FS, CT.

Funding This article was financially supported by the Shiraz University of Medical Sciences (grant no 93-7126).

Competing interests None declared. 
Ethics approval This study was approved by the Research Ethics Committee of Shiraz University of Medical Sciences (EC-93-7126). After the purpose was stated and the methodology was described, written informed consent was obtained from all participants. In all research steps, confidentiality was observed and codes were used to refer to the participants for reporting the findings (S1, N1, I1 and so on). Furthermore, the participants were ensured that they could withdraw from the study at any time. The characteristics of the participants have been presented using code identifiers (S, student; N, nurse; and I, instructor).

Provenance and peer review Not commissioned; externally peer reviewed.

Data sharing statement № additional data are available.

Open access This is an open access article distributed in accordance with the Creative Commons Attribution Non Commercial (CC BY-NC 4.0) license, which permits others to distribute, remix, adapt, build upon this work non-commercially, and license their derivative works on different terms, provided the original work is properly cited, appropriate credit is given, any changes made indicated, and the use is non-commercial. See: http://creativecommons.org/licenses/by-nc/4.0/.

\section{REFERENCES}

1. Henderson A, Twentyman M, Heel A, et al. Students' perception of the psycho-social clinical learning environment: an evaluation of placement models. Nurse Educ Today 2006;26:564-71.

2. Dadgaran I, Parvizy S, Peyrovi H. Nursing students' views of sociocultural factors in clinical learning: a qualitative content analysis. Jpn J Nurs Sci 2013;10:1-9.

3. Egan T, Jaye C. Communities of clinical practice: the social organization of clinical learning. Health 2009;13:107-25.

4. Woodley LK. Clinical teaching in nursing. Teaching in nursing and role of the educator The complete guide to best practice in teaching, evaluation, and curriculum development. New York: Springer Publishing Company, 2013:141-61.

5. Haraldseid C, Friberg F, Aase K. Nursing students' perceptions of factors influencing their learning environment in a clinical skills laboratory: A qualitative study. Nurse Educ Today 2015;35:e1-e6.

6. Reeve KL, Shumaker CJ, Yearwood EL, et al. Perceived stress and social support in undergraduate nursing students' educational experiences. Nurse Educ Today 2013;33:419-24.

7. Dimitriadou M, Papastavrou E, Efstathiou G, et al. Baccalaureate nursing students' perceptions of learning and supervision in the clinical environment. Nurs Health Sci 2015;17:236-42.

8. Tharani A, Husain Y, Warwick I. Learning environment and emotional well-being: A qualitative study of undergraduate nursing students. Nurse Educ Today 2017;59:82-7.

9. Clarke CL, Gibb CE, Ramprogus V. Clinical learning environments: an evaluation of an innovative role to support preregistration nursing placements. Learning in Health and Social Care 2003;2:105-15.

10. Joolaee S, Jafarian Amiri SR, Farahani MA, et al. Iranian nursing students' preparedness for clinical training: A qualitative study. Nurse Educ Today 2015;35:e13-e17.

11. Papp I, Markkanen M, von Bonsdorff M. Clinical environment as a learning environment: student nurses' perceptions concerning clinical learning experiences. Nurse Educ Today 2003;23:262-8.

12. Christiansen A, Bell A. Peer learning partnerships: exploring the experience of pre-registration nursing students. J Clin Nurs 2010;19:803-10.

13. Kermansaravi F, Navidian A, Yaghoubinia F. Nursing students' views of nursing education quality: a qualitative study. Glob $\mathrm{J}$ Health Sci 2015;7:351.

14. Papathanasiou IV, Tsaras K, Sarafis P. Views and perceptions of nursing students on their clinical learning environment: teaching and learning. Nurse Educ Today 2014;34:57-60.

15. Behere SP, Yadav R, Behere PB. A comparative study of stress among students of medicine, engineering, and nursing. Indian $\mathrm{J}$ Psychol Med 2011;33.145.
16. Melincavage SM. Student nurses' experiences of anxiety in the clinical setting. Nurse Educ Today 2011;31:785-9.

17. Joolaee S, Mehrdad N, Bohrani N. A survey on nursing student's opinions toward nursing and reasons for giving it up. Iranian Journal of Nursing Research 2006;1:21-8.

18. Hanifi N, Parvizy S, Joolaee S. Nursing challenges in motivating nursing students through clinical education: A grounded theory study. Nurs Res Pract 2012;2012:1-7.

19. Peyrovi H, Yadavar-Nikravesh M, Oskouie SF, et al. Iranian student nurses' experiences of clinical placement. Int Nurs Rev 2005;52:134-41.

20. Polit DF, Beck CT. Essentials of nursing research: Appraising evidence for nursing practice. Lippincott Williams \& Wilkins, 2010.

21. Strauss A, Corbin J. Basics of qualitative research: Procedures and techniques for developing grounded theory: Thousand Oaks. CA: Sage, 1998.

22. Kermansaravi F, Navidian A, Imani M. Nursing students' views toward quality of theoretical and clinical nursing education: A qualitative Study. Journal of Medical Education and Development 2013;7:28-40.

23. Pourghane P. Nursing students' experiences of clinical teaching: A qualitative study. Journal of Holistic Nursing And Midwifery 2013;23:16-26.

24. Hadizadeh F, Firoozi M, Shamaeyan Razavi N. Nursing and midwifery students perspective on clinical education in Gonabad University of Medical Sciences. Iranian Journal of Medical Education 2005;5:70-8.

25. Price SL. Becoming a nurse: a meta-study of early professional socialization and career choice in nursing. $J$ Adv Nurs 2009;65:11-19.

26. Abazary F, Abbaszadeh A, Arab M. A study on level and sources of stress in nursing students. Strides in Development of medical Education 2004;1:23-31.

27. Mooney M. Facing registration: the expectations and the unexpected. Nurse Educ Today 2007;27:840-7 https://doi.org/.

28. Day RA, Field PA, Campbell IE, et al. Students' evolving beliefs about nursing: from entry to graduation in a four-year baccalaureate programme. 1995. Nurse Educ Today 2005;25:636-43.

29. Adib-Hajbaghery M, Dianati M. Undergraduate nursing students' compatibility with the nursing profession. BMC Med Educ 2005;5.25.

30. Motlagh FG, Karimi M, Hasanpour M. Iranian nursing students' experiences of nursing. Iran J Nurs Midwifery Res 2012;17(2 Suppl 1):S107.

31. Suikkala A, Leino-Kilpi $H$, Katajisto J. Factors related to the nursing student-patient relationship: the students' perspective. Nurse Educ Today 2008;28:539-49.

32. Del Prato D. Students' voices: the lived experience of faculty incivility as a barrier to professional formation in associate degree nursing education. Nurse Educ Today 2013;33:286-90.

33. Nabolsi M, Zumot A, Wardam L, et al. The experience of jordanian nursing students in their clinical practice. Procedia Soc Behav Sci 2012;46:5849-57.

34. Shaban IA, Khater WA, Akhu-Zaheya LM. Undergraduate nursing students' stress sources and coping behaviours during their initial period of clinical training: a Jordanian perspective. Nurse Educ Pract 2012;12:204-9.

35. Younas A. Levels of stress and coping strategies used by nursing students in Asian countries: an integrated literature review. J Middle East North Afr Sci 2016;2 50-57.

36. Chan CK, So WK, Fong DY. Hong Kong baccalaureate nursing students' stress and their coping strategies in clinical practice. J Prof Nurs 2009;25:307-13.

37. Gibbons C. Stress, coping and burn-out in nursing students. Int $J$ Nurs Stud 2010;47:1299-309.

38. Vaghee S, Mirzaie O, Modarres Gharavi M, et al. The effect of communication skills education on nursing students coping strategies in stressful situations of clinical courses. Evidence Based Care 2011;1:91-102. 